\title{
ChemComm
}

\section{A bi-stable $\mathrm{Pt}(\mathrm{II})$ based molecular turnstile $\uparrow$}

Cite this: Chem. Commun., 2015 51,12486

Received 31st May 2015,

Accepted 26th June 2015

DOI: $10.1039 / \mathrm{c5cc04456a}$

www.rsc.org/chemcomm

Playing with the competition between $\mathrm{H}$ - and coordination-bonds, a bi-stable unsymmetrical organometallic turnstile was designed and its dynamic behaviour was studied in solution using NMR techniques. The turnstile, bearing two differentiated interaction sites, is based on a stator, composed of a square planar $\mathrm{Pt}($ (I) centre equipped with one pyridyl group and one phenol moiety, connected to a symmetrical rotor bearing a pyridyl unit as either a $\mathrm{H}$-bond acceptor or as a monodentate coordinating site. Whereas in the absence of a metallic effector, the turnstile is locked by a $\mathrm{H}$-bond formed between the phenol moiety located on the stator and the pyridyl group of the rotor, in the presence of $\mathrm{Ag}^{+}$cations, the turnstile switches to another closed state resulting from the simultaneous binding of the cations by pyridyl units belonging to both the stator and the rotor. The switching process was shown to be reversible.

Controlling translational or rotational intramolecular movements within abiotic molecular entities is a topic of current interest. ${ }^{1}$ Among many systems reported, a class of molecules called molecular turnstiles ${ }^{2}$ is of particular interest for the design of bi-stable dynamic entities displaying an open and a closed state with the possibility of switching between the two by an external stimuli.

For some time now, our group has been investigating the design and synthesis of molecular turnstiles. Thus, we have reported a series of porphyrin based dynamic systems. ${ }^{3}$ We have also extended our approach to organic turnstiles with optical reading of their open and closed states. ${ }^{4}$ Finally, inspired by contributions on molecular gyroscopes by Gladysz et al. ${ }^{5}$ we have reported a series of organometallic turnstiles based on $\mathrm{Pt}(\mathrm{II}){ }^{6}{ }^{6}$ Molecular turnstiles reported so far are dynamic entities based on open and closed states. To the best of our knowledge, no example

Molecular Tectonics Laboratory, UMR UDS-CNRS, 7140 \& icFRC, Université de Strasbourg, F-67000, Strasbourg, France. E-mail: hosseini@unistra.fr;

Fax: +33 368851325; Tel: +33368851323

$\dagger$ Electronic supplementary information (ESI) available: Experimental details, full characterisation of new compounds, NMR and mass spectra. See DOI: 10.1039/ c5cc04456a
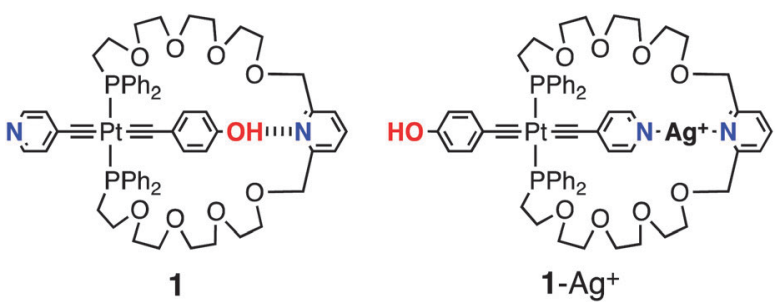

Fig. 1 The two closed states of the unsymmetrical turnstile 1 (C1) and its silver complex 1- $\mathrm{Ag}^{+}(\mathrm{C} 2)$.

of turnstiles undergoing a switch between two closed states has been reported.

Herein we report the design, synthesis and solution study of a Pt(II)-based organometallic turnstile and the switching between its two different closed states based either on H-bonding or coordination process (Fig. 1).

The design of the turnstile $\mathbf{1}$ (Scheme 1) is based on a square planar Pt(II) centre as a hinge, bearing two different sites, a phenol as a H-bond donor and a pyridyl moiety as a monodentate coordinating site. This ensemble may be regarded as the stator. The latter is equipped with a symmetric rotor also bearing a pyridyl group as either a H-bond acceptor site or as a monodentate coordinating group. The connection of the two sites located on the $\mathrm{Pt}(\mathrm{II})$ based stator is ensured by $\mathrm{Pt}-\mathrm{C}$ bonds using two alkynyl units and the position 4 of both phenol and pyridine moieties. The rotor is connected to the stator by two Pt-P bonds using an $\alpha, \omega$-bis-diphenylphosphine fragment bearing a pyridyl unit at its centre. The interconnection between the pyridyl moiety and the two phosphine groups is ensured by two tetraethyleneglycol spacers using positions 2 and 6 of the aromatic group. The choice of stator and rotor terminology is arbitrary and may be reversed.

In principle, in the absence of a metal centre as the effector, the turnstile 1 should be in its closed state $\mathrm{C} 1$ resulting from the establishment of a $\mathrm{H}$-bond between the phenol group of the stator and the pyridyl moiety belonging to the rotor. Upon the addition of an effector such as $\mathrm{Ag}^{+}$cations, owing to the higher 


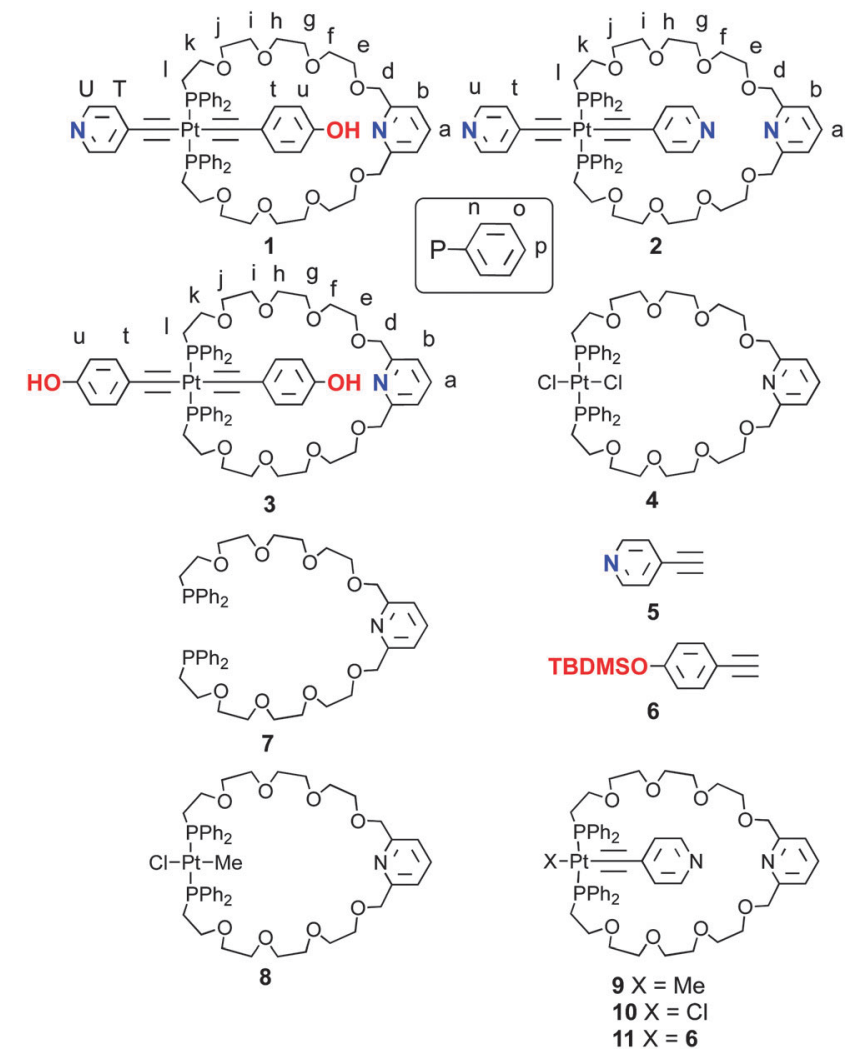

Scheme 1 Structures of compounds 1-11 and assignments of the $\mathrm{H}$-atoms for turnstiles $1-3$.

stability constant of the silver complex when compared to the $\mathrm{H}$-bonded state, the turnstile should switch to a second closed state $\mathrm{C} 2$ based on the simultaneous binding of the cations by both pyridyl moieties belonging to the stator and the rotor (Fig. 1).

The synthesis (see ESI $\dagger$ ) of the unsymmetrical turnstile 1 appeared to be rather challenging and required the exploration of three different synthetic strategies. The first one, statistical in nature, was based on the condensation at $55{ }^{\circ} \mathrm{C}$ of the metallamacrocycle $4^{6 a}$ with the ethynylpyridine $5^{7}$ and the protected ethynylphenol derivative $6^{8}$ (1.5 eq. of each) in the presence of a catalytic amount of $\mathrm{CuI}$ in a $\mathrm{THF} / \mathrm{NEt}_{3}$ mixture. As expected, the reaction afforded all three macrocyclic compounds: the desired unsymmetrical compound 1, and the two symmetrical turnstiles $2^{6 a}$ and 3. Unfortunately, their separation was found to be unfeasible. However, upon deprotection of the phenol moiety using TetraButylAmmonium Fluoride (TBAF) at room temperature, the separation, although very tedious, could be achieved affording thus the desired turnstile 1 in $3.5 \%$ yield.

The second strategy, more directed, was based on the condensation of $\mathrm{CODPtMeCl}^{9}$ with the diphenylphosphine compound $7^{6 a}$ under high dilution conditions. The reaction produced the intermediate 8 in $92 \%$ yield. The condensation of the latter with ethynyl pyridine $5^{7}$ afforded the compound 9 with $c a .5-10 \%$ of the symmetrical bispyridyl turnstile 2 . After substitution of the methyl group by chloride using $\mathrm{HCl}$ leading to the compound $\mathbf{1 0}$, the latter was condensed with the protected phenol $6 .{ }^{8}$ Again, the purification appeared to be very tedious. In order to overcome this, the TBDMS protective group was removed. After column chromatography and purifying several times by PTLC, the desired turnstile 1 was obtained in 6\% yield (over the three last synthetic steps).

Finally, a third synthetic strategy was explored. This was based on mono-alkylation of the Pt(II)-metallamacrocycle 4 upon its reaction with stannylated 4-ethynylpyridine, generated in situ upon successive additions of $n \mathrm{BuLi}$ and $\mathrm{SnMe}_{3} \mathrm{Cl}^{10}$ The condensation afforded compound 10. The reaction of the latter with 6 afforded the protected intermediate metallamacrocycle 11 which, upon deprotection using TBAF, afforded the desired turnstile 1 in 13\% yield over the last three synthetic steps. The rather low yield reported for $\mathbf{1}$ corresponds to the isolated compound and results from the purification method, mainly, chromatography which appeared to be the only possible one.

The switching between the two $\mathrm{C} 1$ and $\mathrm{C} 2$ closed states of the unsymmetrical turnstile 1 (Fig. 1) was studied in $\mathrm{CD}_{2} \mathrm{Cl}_{2}$ solution using 1- and 2-D NMR techniques. All the $\mathrm{H}$-atoms of 1 were assigned (Scheme 1).

For the turnstile 1, chemical shifts (ppm) $\mathrm{H} t$ and $\mathrm{H} u$ of the phenol moiety and $\mathrm{H}_{T}$ and $\mathrm{H} U$ of the pyridyl group appeared at $6.95,6.62$ and $6.23,8.09$ respectively. For the phenol group, the chemical shifts observed are downfield shifted when compared to signals for the symmetrical bis-phenol turnstile 3 ( $\mathrm{H} t 6.60$ and $\mathrm{H} u$ 6.51). The chemical shifts for $\mathrm{H}_{T}$ and $\mathrm{H} U$ of the pyridyl moiety of $\mathbf{1}$ are close to those observed for the unbound pyridyl group of $2-\mathrm{Ag}^{+}$at low temperature. ${ }^{6 a}$ Finally, the chemical shifts observed for $\mathrm{H} a$ (7.75) and $\mathrm{H} b$ (7.37) atoms of the pyridyl group located on the rotor in $\mathbf{1}$ are similar to those observed for the bis-phenol turnstile 3 . These observations indicate the formation of a $\mathrm{H}$-bond between the phenol moiety of the stator ( $\mathrm{H}$ bond donor) and the pyridyl group of the rotor $(\mathrm{H}$ bond acceptor) leading thus to the peripheral positioning of the pyridyl unit of the stator with respect to the macrocyclic cavity.

Observations obtained by $1 \mathrm{D}{ }^{1} \mathrm{H}-\mathrm{NMR}$ investigations mentioned above were further confirmed by ${ }^{1} \mathrm{H}-{ }^{1} \mathrm{H}$ ROESY NMR experiments (Fig. 2). The chemical shift of the signals in the regions corresponding to the aromatic and ethylene glycol $\mathrm{H}$ atoms shows cross-relaxation peaks between $\mathrm{H} t$ and $\mathrm{H} u$ of

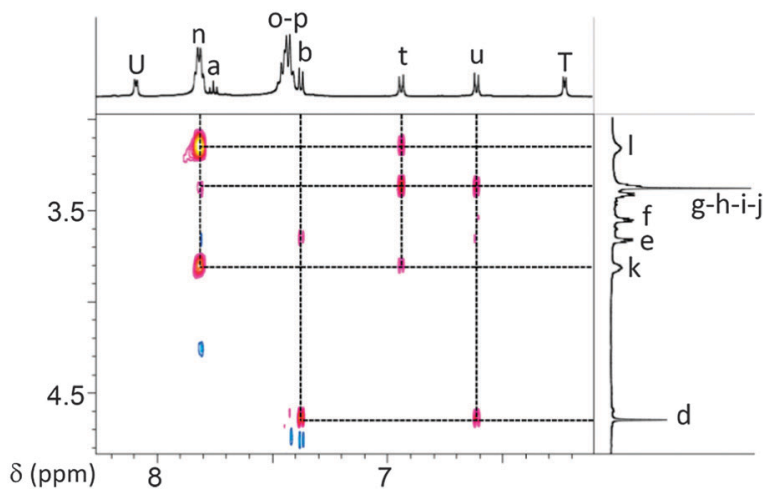

Fig. 2 Portion of the ${ }^{1} \mathrm{H}-{ }^{1} \mathrm{H}$ ROESY spectra of $1\left(\mathrm{CD}_{2} \mathrm{Cl}_{2}, 500 \mathrm{MHz}, 298 \mathrm{~K}\right)$. For signal assignments, see Scheme 1. 

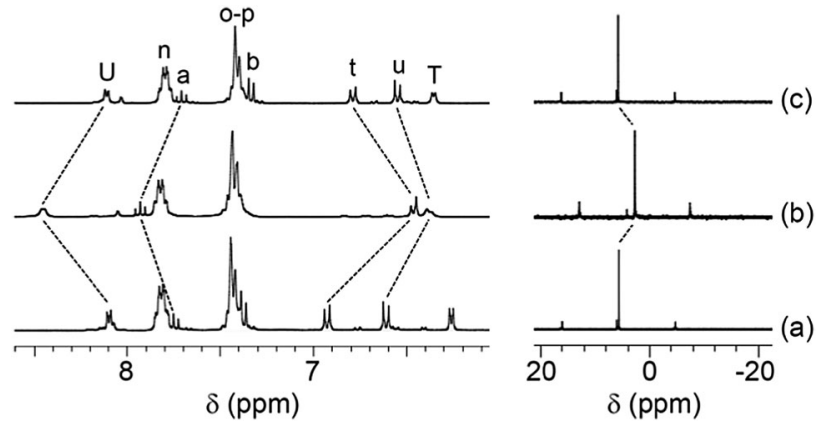

Fig. 3 Portions of the ${ }^{1} \mathrm{H}-\mathrm{NMR}$ (left) and ${ }^{31} \mathrm{P}-\mathrm{NMR}$ (right) $\left(\mathrm{CD}_{2} \mathrm{Cl}_{2}, 298 \mathrm{~K}\right.$ ) spectra for $\mathbf{1}(\mathrm{a}), \mathbf{1}-\mathrm{Ag}^{+}(\mathrm{b})$ and $\mathbf{1}-\mathrm{Ag}^{+}$after the addition of one equivalent of $\mathrm{Br}^{-}$anions (c). For signal assignments, see Scheme 1.

the phenol moiety and $\mathrm{H} d-j-k-l$ of the handle. As expected, no cross-relaxation peaks between $\mathrm{H}_{T}$ and $\mathrm{H} U$ of the pyridyl moiety of the stator and $\mathrm{H} d-j-k-l$ atoms of the handle were observed. This indeed confirms that the turnstile $\mathbf{1}$ is locked in the closed state C1.

The switch between the two closed states $\mathrm{C} 1$ and $\mathrm{C} 2$ was achieved upon addition of $\mathrm{Ag}^{+}$cations as an effector. Indeed, addition of one equivalent of $\mathrm{AgSbF}_{6}$ in $\mathrm{CD}_{3} \mathrm{CN}$ to a solution of 1 in $\mathrm{CD}_{2} \mathrm{Cl}_{2}$, caused significant changes in the ${ }^{1} \mathrm{H}$ NMR spectra of the turnstile, especially in the aromatic region (Fig. 3a and b, left). Hydrogen atoms of the stator are all strongly affected, with shifts (ppm) of $-0.46,-0.23$ and $+0.36 \mathrm{ppm}$ for $\mathrm{H} t, \mathrm{H} u$ and $\mathrm{H} u$, respectively. It should be noticed that the signal corresponding to $\mathrm{H} T$ is hidden under the $\mathrm{Ho}-p$ signals. This is in agreement with the previous observation of the signal at $7.5 \mathrm{ppm}$ for $2-\mathrm{Ag}^{+}$ at a low temperature. ${ }^{6 a}$ Furthermore, the signal corresponding to $\mathrm{H} a$ is downfield shifted $(\delta=7.94 \mathrm{ppm})$ upon binding of $\mathrm{Ag}^{+}$ cations. Again, this is in agreement with previous observation for $2-\mathrm{Ag}^{+}$for which the signal corresponding to $\mathrm{H} a$ appears at 7.96 ppm. $^{6 a}$ These observations imply the simultaneous binding of the silver cations by both pyridyl units belonging to the stator and the rotor.

Again, the above-mentioned conclusions are further confirmed by 2D NOESY experiments. Indeed, the ${ }^{1} \mathrm{H}-{ }^{1} \mathrm{H}$ NOESY spectrum (Fig. 4) reveals the absence of correlations between

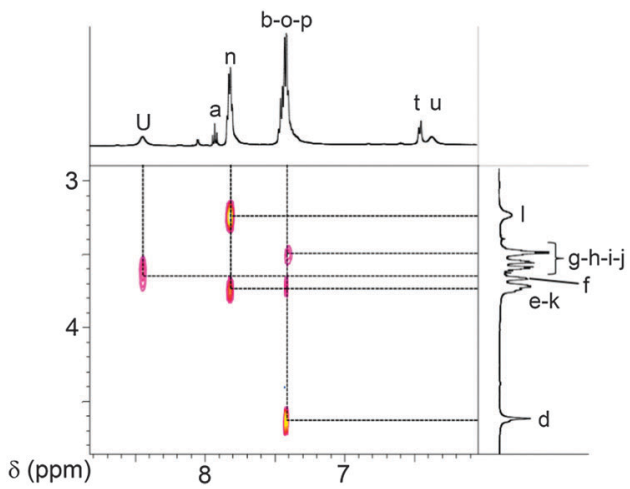

Fig. 4 Portion of the ${ }^{1} \mathrm{H}-{ }^{1} \mathrm{H}$ NOESY spectrum for $1-\mathrm{Ag}^{+}\left(\mathrm{CD}_{2} \mathrm{Cl}_{2}, 500 \mathrm{MHz}\right.$, 298 K). For signal assignments, see Scheme 1. the phenolic hydrogen atoms $\mathrm{H} t$ and $\mathrm{H} u$ of the stator and hydrogen atoms of the handle. This indicates that the phenol moiety is located outside of the macrocyclic backbone. Furthermore, as expected, $\mathrm{H} u$ correlates with $\mathrm{H} f$.

The stoichiometry of the binding of silver cations by the turnstile 1 was investigated by mass spectrometry by addition of increasing amounts of $\mathrm{AgSbF}_{6}$, to a $\mathrm{CH}_{2} \mathrm{Cl}_{2}$ solution of 1 (see $\mathrm{ESI} \dagger$ ). For the $1 / 1$ ratio of $\mathrm{Ag}^{+}$and $\mathbf{1}$, the main product obtained is $1-\mathrm{Ag}^{+}$. Upon increasing the ratio to 2 or 3 , no trace of dicationic species was present; however, degradation of the complex was observed, which was not further investigated.

The reversibility of the switching process between the two closed states $\mathrm{C} 1$ and $\mathrm{C} 2$ was achieved upon the addition of one equivalent of $\mathrm{Et}_{4} \mathrm{NBr}$ to a solution of $1-\mathrm{Ag}^{+}$followed by the filtration of the precipitated $\mathrm{AgBr}$ salt. The process was monitored by both ${ }^{1} \mathrm{H}$ - and ${ }^{31} \mathrm{P}-\mathrm{NMR}$ studies (Fig. 3). Indeed, chemical shifts for signals corresponding to $\mathrm{H} t, \mathrm{H} u, \mathrm{H} t, \mathrm{H} u$, $\mathrm{H} a$ and $\mathrm{H} b$ atoms were identical to those observed for $\mathbf{1}$ (Fig. 3, left). The same behaviour was observed when monitoring the process by ${ }^{31} \mathrm{P}$-NMR (Fig. 3, right).

The solution dynamic behaviour of the symmetrical bis-phenol turnstile 3 was also studied by 1- and 2-D NMR. In that case, as for the unsymmetrical turnstile $\mathbf{1}$, one would expect a closed state resulting from the formation of a $\mathrm{H}$-bond between one of the two phenol units of the stator and the pyridyl group of the rotor. However, as previously observed for the other symmetrical turnstile 2 in the presence of silver cations, ${ }^{6 a}$ owing to the rather weak nature of the $\mathrm{H}$ bond, one would expect an oscillation between two equivalent closed states. At room temperature in $\mathrm{CD}_{2} \mathrm{Cl}_{2}$, the two phenol groups were found to be equivalent as only a single set of signals was observed for the $\mathrm{H} t$ and $\mathrm{H} u$ atoms (Fig. 5). This implies either the absence of the $\mathrm{H}$-bond and thus the open state of the turnstile 3 or a rapid exchange between two equivalent closed states resulting from the formation of a $\mathrm{H}$ bond. In order to investigate the exchange process, variable temperature NMR studies have been carried out. Unfortunately, lowering the temperature to $-46{ }^{\circ} \mathrm{C}$ did not allow the observation of the splitting of $\mathrm{H}$ atoms belonging to the two phenol groups into $\mathrm{H} t$ and $\mathrm{H} u$ and $\mathrm{H} t^{\prime}$ and $\mathrm{H} u^{\prime}$ as one would expect for the phenol involved in the $\mathrm{H}$ bond formation and the free phenol respectively. In order to enhance the strength of the $\mathrm{H}$-bond, the ${ }^{1} \mathrm{H}$-NMR spectrum was recorded in a less polar mixture of solvents $\left(\mathrm{CD}_{2} \mathrm{Cl}_{2} / \mathrm{CCl}_{4} 1 / 1\right)$.

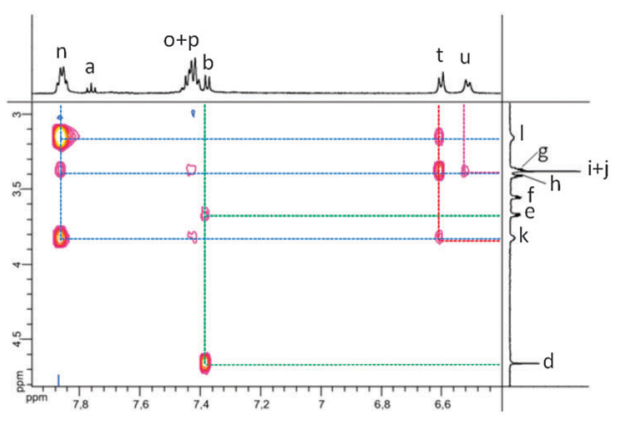

Fig. 5 Portion of the ${ }^{1} \mathrm{H}-{ }^{1} \mathrm{H}$ ROESY spectra $\left(\mathrm{CD}_{2} \mathrm{Cl}_{2}, 600 \mathrm{MHz}, 298 \mathrm{~K}\right)$ for the turnstile 3 . For signal assignments, see Scheme 1. 


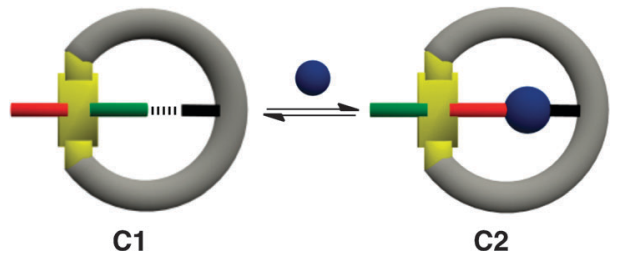

Fig. 6 Schematic representations of the two closed states $\mathrm{C} 1$, based on a $\mathrm{H}$-bond between the phenol of the stator and the pyridyl units of the rotor, and $\mathrm{C} 2$ resulting from the simultaneous binding of silver cations by both pyridyl groups belonging to the stator and the rotor.

Unfortunately, the turnstile $\mathbf{3}$ appeared to be insoluble below $-20{ }^{\circ} \mathrm{C}$. The existence of the closed state of the turnstile 3 was demonstrated by $2 \mathrm{D}{ }^{1} \mathrm{H}-{ }^{1} \mathrm{H}$ NOESY NMR that clearly revealed the presence of correlations peaks between the $\mathrm{H} t$ and $\mathrm{H} u$ atoms of the phenol ring and the $\mathrm{H}$ atoms of $-\mathrm{OCH}_{2}-$ groups of the rotor (Fig. 5).

In conclusion, the unsymmetrical organometallic turnstile 1, based on a Pt(II) centre bearing a phenol and a pyridyl and connected to a symmetrical handle, displays two distinct closed states resulting either from the establishment of a $\mathrm{H}$-bond between the phenol moiety and the pyridyl unit (C1) or the simultaneous binding of silver cations by both pyridyl units belonging to the stator and the rotor (C2). The switching between the two states is reversible and may be achieved by adding $\mathrm{Br}^{-}$anions, which leads to the precipitation of the insoluble $\mathrm{AgBr}$ salt. Based on the principle described in this contribution, the design of other organometallic turnstiles and metallic effectors is currently under investigation (Fig. 6).

This contribution was financially supported by the University of Strasbourg, the International Centre for Frontier Research in Chemistry (icFRC), Strasbourg, the Institut Universitaire de France, the CNRS and the Ministry of Education and Research (PhD fellowship to N. Z.).

\section{Notes and references}

1 (a) J.-P. Sauvage, Science, 2001, 291, 2105; (b) J.-P. Sauvage, Acc. Chem. Res., 1998, 31, 611; (c) J.-P. Sauvage, in Molecular machines and motors, structure and bonding, ed. J.-P. Sauvage, Springer, Berlin, Heidelberg, vol. 99, 2001, pp. 1-282; (d) V. Balzani, M. Venturi and A. Credi, Molecular devices and machines: a journey into the nanoworld, Wiley-VCH, Weinheim, 2003, pp. 1-457; (e) T. R. Kelly, in Molecular machines, Topics in Current Chemistry, ed. T. R. Kelly, vol. 262, Springer, Berlin, Heidelberg, 2005, pp. 1-227; $(f)$ Y. Shirai, J.-F. Morin, T. Sasaki, J. M. Guerrero and J. M. Tour, Chem. Soc. Rev., 2006, 35, 1043; $(g)$ E. R. Kay, D. A. Leigh and F. Zerbetto, Angew. Chem., Int. Ed., 2007, 46, 72; (h) N. Koumura, R. W. J. Zijlstra, R. A. van Delden, N. Harada and B. L. Feringa, Nature, 1999, 401, 152; (i) V. Balzani, A. Credi, F. M. Raymo and J. F. Stoddart, Angew. Chem., Int. Ed., 2000, 39, 3348; (j) C. A. Schalley, K. Beizai and F. Vögtle, Acc. Chem. Res., 2001, 34, 465; (k) J. Michl and E. C. H. Sykes, ACS Nano, 2009, 3, 1042; (l) G. Vives and J. M. Tour, Acc. Chem. Res., 2009, 42, 473; $(m)$ N. Weibel, A. Mishchenko, T. Wandlowski, M. Neuburger, Y. Leroux and M. Mayor, Eur. J. Org. Chem., 2009, 6140; (n) S. Sengupta, M. E. Ibele and A. Sen, Angew. Chem., Int. Ed., 2012, 51, 8434; (o) C. Clavel, C. Romuald, E. Brabet and F. Coutrot, Chem. - Eur. J., 2013, 19, 2982.

2 (a) T. C. Bedard and J. S. Moore, J. Am. Chem. Soc., 1995, 117, 10662; (b) A. Carella, J. Jaud, G. Rapenne and J.-P. Launay, Chem. Commun., 2003, 2434; (c) N. Weibel, A. Mishchenko, T. Wandlowski, M. Neuburger, Y. Leroux and M. Mayor, Eur. J. Org. Chem., 2009, 6140.

3 (a) A. Guenet, E. Graf, N. Kyritsakas, L. Allouche and M. W. Hosseini, Chem. Commun., 2007, 2935; (b) A. Guenet, E. Graf, N. Kyritsakas and M. W. Hosseini, Inorg. Chem., 2010, 49, 1872; (c) A. Guenet, E. Graf, N. Kyritsakas and M. W. Hosseini, Chem. - Eur. J., 2011, 17, 6443; (d) T. Lang, A. Guenet, E. Graf, N. Kyritsakas and M. W. Hosseini, Chem. Commun., 2010, 46, 3508; (e) T. Lang, E. Graf, N. Kyritsakas and M. W. Hosseini, Dalton Trans., 2011, 40, 3517; $(f)$ T. Lang, E. Graf, N. Kyritsakas and M. W. Hosseini, Dalton Trans., 2011, 40, 5244; $(g)$ T. Lang, E. Graf, N. Kyritsakas and M. W. Hosseini, Chem. - Eur. J., 2012, 18, 10419; (h) T. Lang, E. Graf, N. Kyritsakas and M. W. Hosseini, New J. Chem., 2013, 37, 112.

4 N. Zigon, P. Larpent, A. Jouaiti, N. Kyritsakas and M. W. Hosseini, Chem. Commun., 2014, 50, 5040.

5 (a) A. J. Nawara, T. Shima, F. Hampel and J. A. Gladysz, J. Am. Chem. Soc., 2006, 128, 4962; (b) K. Skopek, M. C. Hershberger and J. A. Gladysz, Coord. Chem. Rev., 2007, 251, 1723; (c) T. Shima, E. B. Bauer, F. Hampel and J. A. Gladysz, Dalton Trans., 2004, 1012; (d) E. B. Bauer, F. Hampel and J. A. Gladysz, Organometallics, 2003, 22, 5567; (e) P. D. Zeits, G. P. Rachiero, F. Hampel, J. H. Reibenspies and J. A. Gladysz, Organometallics, 2012, 31, 2854.

6 (a) N. Zigon, A. Guenet, E. Graf and M. W. Hosseini, Chem. Commun., 2013, 49, 3637; (b) N. Zigon, A. Guenet, E. Graf, N. Kyritsakas and M. W. Hosseini, Dalton Trans., 2013, 43, 9740; (c) N. Zigon, N. Kyritsakas and M. W. Hosseini, Dalton Trans., 2013, 43, 152.

7 L. Yu and J. S. Lindsey, J. Org. Chem., 2001, 66, 7402.

8 (a) G. Y. Fang and V. K. Aggarwal, Angew. Chem., Int. Ed., 2007, 46, 359; (b) T. Ogawa, K. Ohta, T. Iijima, T. Suzuki, S. Ohta and Y. Endo, Bioorg. Med. Chem., 2009, 17, 1109; (c) S. K. Chitneni, C. M. Deroose, J. Balzarini, R. Gijsbers, S. Celen, Z. Debyser, L. Mortelmans, A. M. Verbruggen and G. M. Bormans, J. Med. Chem., 2007, 50, 6627.

9 G. P. C. M. Dekker, A. Buijs, C. J. Elsevier, K. Vrieze, P. W. N. M. Van Leeuwen, W. J. J. Smeets, A. L. Spek, Y. F. Wang and C. H. Stam, Organometallics, 1992, 11, 1937.

10 M. Hissler, A. Harriman, A. Khatyr and R. Ziessel, Chem. - Eur. J., 1999, 5, 3366. 